\title{
El diario de Gabriel Quiroga: reflexiones de Manuel Gálvez ante el centenario de la Revolución de Mayo
}

\author{
[The Diary of Gabriel Quiroga: Reflections by Manuel Galvez to the \\ Centenary of the May Revolution]
}

\author{
Gonzalo Rubio García \\ (UBA-CONICET-GEHiGue) \\ gonza_rubio@hotmail.com
}

\begin{abstract}
Resumen:
El diario de Gabriel Quiroga fue una obra escrita a principios del siglo XX por Manuel Gálvez que, como veremos, logró calar hondo en el pensamiento de la población argentina. A su vez, es un texto que ha sido destacado por muchos intelectuales debido a sus apelaciones al nacionalismo cultural y las nociones de corte positivista, así como también sus aportes modernistas y anti positivistas. Por dicha razón, ante la diversidad de construcciones encontradas, nuestro objetivo en este trabajo es indagar y revisar las ideas que el autor sostuvo en esta obra, teniendo en cuenta que se trata de su primer acercamiento literario hacia la crítica del pasado argentino y el género de diario ficcional. Consideramos que la estrategia elegida permitió al autor destacar un personaje, representativo de otros hombres en su época, que era habilitado por la matriz realista de la obra. Bajo ese formato, logró que las posturas expuestas sirvieran como una construcción fidedigna de muchas de las ideas que circulaban en la época del Centenario y como antecedente intelectual para otros pensadores que posteriormente adhirieron al nacionalismo.
\end{abstract}

Palabras claves: Manuel Gálvez; Nacionalismo; Modernismo; Diario de Escritor

\begin{abstract}
:
The Diario de Gabriel Quiroga was written at the beginning of the 20th century by Manuel Gálvez that, as we will see, managed to penetrate deep into the ideas of the Argentine population. In turn, it is a text that has been highlighted by many intellectuals due to its appeals to cultural nationalism and positivist topics, as well as its modernist and anti-positivist contributions. For this reason, given the diversity of constructions found, our objective in this work is to investigate and review the ideas that the author sustained in this work, bearing in mind that this is his first literary approach to criticism of the Argentine past and the genre of fictional diary chosen for the writing. We consider that the chosen strategy allowed the author to highlight a character, representative of other men in his time, who was enabled by the realistic matrix of the work. Under this format, he achieved that the positions exposed in his writing served as a reliable construction of many of the ideas that circulated in the Centennial era and as an intellectual antecedent for other intellectuals who later adhered to nationalism.
\end{abstract}

Keywords: Manuel Gálvez; Nationalism; Modernism; Writer's Diary

Recibido: 03/06/19

Evaluación: 03/03/20

Aceptado: 17/03/20

Anuario de la Escuela de Historia Virtual - Año 11 - № 17 - 2020: pp. 57-78.

ISSN: 1853-7049

http://revistas.unc.edu.ar/index.php/anuariohistoria 


\section{El diario de Gabriel Quiroga: reflexiones de Manuel Gálvez ante el centenario de la Revolución de Mayo*}

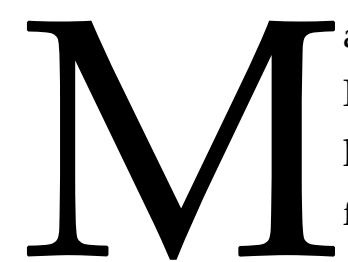

anuel Gálvez (1882-1962) fue un escritor nacido en la ciudad de Paraná que logró tener un papel trascendental en el ambiente literario a comienzos del siglo XX. ${ }^{1}$ Procedente de una prestigiosa familia acaudalada de la provincia de Santa Fe, no solo se destacó por sus obras y descripciones críticas sobre la sociedad argentina de principios del siglo $X X$, sino también por su defensa de la profesionalización del oficio de escritor y la activa promoción que realizó de sus distintas empresas culturales, iniciativas que llevaron a considerar su figura, junto a las de Leopoldo Lugones y Ricardo Rojas, como la de un portaestandarte de la generación del Centenario.

En el presente artículo buscaremos analizar las nociones que Gálvez desarrolló en El diario de Gabriel Quiroga: opiniones sobre la vida argentina (1910), texto que consideraremos desde su formato de diario ficcional. Se trata de una obra relevante -a pesar del pobre éxito de ventas que tuvo su primera edición- para entender las ideas que circulaban en la época del Centenario. Nuestro objetivo en este artículo es analizar las posturas que el autor sostuvo en el escrito teniendo en cuenta el formato utilizado, el contexto de época en que fue realizado, la circulación de ideas con otros intelectuales, la utilización del pasado en las argumentaciones y la impronta que logró al momento de su edición. La obra ha sido destacada por sus apelaciones nacionalistas, antipositivistas, positivistas, realistas y modernistas, cuestión que hace necesario un análisis profundo de la obra por el impacto que tuvieron esas ideas con posterioridad en los círculos nacionalistas (Terán, 2008, pp. 162, 164-165; Gramuglio, 2001, pp. 162167).

La tarea será llevada adelante tomando en cuenta no solo la obra en cuestión, sino también distintos escritos que Gálvez publicó antes y después de 1910. Esto ayudará a comprender la evolución de su pensamiento, las lecturas y la circulación de ideas que logró generar junto a otros intelectuales. Sin embargo, no se hará hincapié en el estilo realista del autor, pues, como podremos observar a continuación, abundan los trabajos que han estudiado la obra profundizando en las características de esa estética.

Si bien muchos han estudiado El diario de..., los escritos sobre las ideas allí expuestas en relación a la faceta "diarística" han sido escasamente trabajados. Muchos autores, como Noé Jitrik, han exaltado su estética realista, pero sin hacer demasiado hincapié en las nociones irracionalistas -más cercanas al modernismo anti imperialista de finales del siglo XIX- que supo guardar en torno al Centenario (Jitrik, 1969, pp. 15, 18-19, 20-

\footnotetext{
* Agradezco los comentarios y sugerencias para este trabajo de Claudia Román.

${ }^{1}$ Algunas de sus obras más conocidas fueron $E l$ mal metafísico (1916), Nacha Regules (1919), El general Quiroga (1932), entre otras.
}

Anuario de la Escuela de Historia Virtual - Año 11 - Nº 17 - 2020: pp. 57-78. ISSN: 1853-7049 
21). Además, analizó levemente las posturas sobre la Historia y el nacionalismo que Gálvez mostró en sus obras, siendo aquellos dos puntos importantes para comprender su pensamiento. Algo similar sucede con el estudio de Alberto Julián Pérez: aunque realizó un análisis más completo sobre El diario de..., no hizo hincapié en el formato de diario, a la vez que colocó las ideas allí expuestas, al igual que Jitrik, dentro de los parámetros "biologicistas y positivistas", dejando un escaso margen para el análisis de sus posturas espiritualistas, antagónicas en gran medida con las corrientes filosóficas mencionadas (Pérez, 2006, pp. 4, 9). Fuera de la anterior cuestión, el análisis de Pérez destacó de forma acertada la función que cumplía el personaje de Gabriel Quiroga al mostrarlo como un "joven moderno" que había optado por el abandono del cosmopolitismo para convertirse en un patriota, siendo aquel el punto de partida del texto para mostrar las debilidades de los argentinos (Pérez, 2006, p. 6).

Una lógica parecida a las anteriores tomó Francesca Camurati al ignorar el formato de diario y considerar al autor mediante el positivismo filosófico. De todas formas, debemos rescatar la subversión que mostró Camurati respecto al paradigma de civilización-barbarie y campo-ciudad. Gálvez logró ubicar el alma argentina, o al menos su posible restauración, en las ciudades del interior, destacando los "espacios contaminados por los aportes externos" en las ciudades. Configuró al interior del país como un reservorio de valores del pasado que era necesario exaltar (Camurati, 2006, pp. 130-133). Sobre las ideas positivistas, otros autores como Mónica Quijada, Carlos Payá y Eduardo Cárdenas, caracterizaron a Gálvez dentro de la "reacción al positivismo" realizada a partir de convicciones irracionalistas, elección que les permitió estudiar la obra desde un marco más amplio (Quijada, 1985, p. 29; Payá y Cárdenas, 1978, pp. 73, 76, 118).

Otros autores, como Marysa Navarro Gerassi y Mónica Quijada, han estudiado el nacionalismo de Gálvez, pero desde una postura que intenta entender dicho fenómeno a partir de distintas clasificaciones que terminan encasillando al escritor dentro de un esquema nacionalista más bien invariable, cuando, en realidad, su pensamiento fue cambiando a lo largo de los años, una cuestión inevitable en la mayoría de los intelectuales (Navarro Gerassi, 1968, pp. 15-17, 37, 55; Quijada, 1985, p. 9). En este aspecto, Pérez afirmó que nuestro autor presentó "el desarrollo de una derecha nacional" que revalorizó el pasado a partir de "la crítica a la política liberal triunfante" idealizando la figura del caudillo Juan Manuel de Rosas (Pérez, 2006, pp. 4, 9). Ese análisis, sin ser desacertado, quizá debe circunscribirse a los primeros años de la carrera de Gálvez. ${ }^{2}$

Respecto al tema, debemos tener en cuenta que las ideas de los nacionalistas argentinos fueron cambiando a lo largo de los años (Rubio García, 2016, pp. 63-74). Si

\footnotetext{
${ }^{2}$ Además de los anteriores estudios, se tornan ineludibles las obras sobre Gálvez de Hebe Clementi, quien consideró acertadamente los escritos de Gabriel Quiroga desde su formato de diario, y la Tesis de Graciela Goldchluk, quien analizó atinadamente a Quiroga desde los tópicos modernistas y decadentistas (Clementi, 2001, pp. 49-60; Goldchluk, 1996, pp. 33-42).
} 
bien no será analizado en profundidad, consideramos que se debe deslindar el camino transitado por muchos historiadores, pues han categorizado los distintos tipos de nacionalismo bajo esquemas simplistas que solo han logrado confundir el estudio sobre esa temática. Por dicha razón, es prudente seguir las posturas de María Inés Tato y Alejandro Cattaruzza, quienes se desentendieron de los esquemas planteados y establecieron los usuales contactos que había entre los nacionalistas, siendo común en la década de 1930 la proliferación de los "grises ideológicos" y los cambios de actitud política entre los intelectuales (Tato, 2009, pp. 158, 162-165; Cattaruzza, 2003, pp. 145$146,160){ }^{3}$

Más allá de los escritos que encontramos sobre el tema, la tarea propuesta al inicio del artículo debe realizarse considerando la función de intelectual que cumplía nuestro autor. Dicho término ha recibido distintos usos desde finales del siglo XIX. El papel de Gálvez dentro de ese terreno - por ser un hombre de ideas que interpelaba a la opinión pública, mediante discursos y ensayos, con una misión cultural- estaba recortado por la configuración histórica de su tiempo y por aquellos otros pensadores con los que dialogaba.

Circunscribimos el tipo de investigación que pretendemos desarrollar dentro del campo de estudios de la historia intelectual. La referencia como "campo" no es casual, ya que si bien se "inscribe su labor dentro de la historiografía (...) a veces, cruza el límite y se mezcla con otras disciplinas", logrando una transversalidad que pretende aflorar "aspectos no percibidos" (Burke, 2017, p. 25; Altamirano, 2005, p. 10; Altamirano, 2013, pp. 17, 73 y 113-115). Entendemos que los aspectos culturales deben analizarse mediante esa parte de la historiografía que busca comprender las ideas y creencias del pasado -los conceptos, palabras y representaciones sociales- utilizando escritos que restituyan la visión que los seres humanos tenían de su época, pero siendo precavidos de no caer en anacronismos al momento de leer las fuentes históricas, pues hay conceptos naturalizados en nuestra vida cotidiana -como, por ejemplo, nación, patria, entre otros- cuyo significado era distinto en el pasado (Chiaramonte, 2013, p.

\footnotetext{
${ }^{3}$ Los intelectuales nacionalistas sufrieron distintos cambios en su manera de pensar y entender el mundo a lo largo de la historia. Dicha característica fue usual entre quienes vivieron los vaivenes económicos y políticos -nacionales e internacionales- en la Argentina de principios del siglo XX. Basta con tomar en cuenta las figuras de Gálvez o los hermanos Irazusta para comprender que sus apreciaciones a finales de la década de 1920 no eran del todo similares a las que supieron guardar una década más tarde. Es probable que las consideraciones sobre los nacionalistas deban tomarse individualmente, haciendo hincapié en la cosmovisión de cada autor y teniendo en cuenta, además, la circulación de ideas entre intelectuales. No negamos la similitud de posturas que tuvieron los nacionalistas. Pero es evidente que los límites ideológicos no estaban esquemáticamente planteados: dependiendo el contexto de época -factor esencial para cualquier análisis histórico- los autores que gravitaron en torno al nacionalismo tuvieron acercamientos y diferencias. Un estudio sobre las particularidades que guardaban generaría un cúmulo de información que podría favorecer un entendimiento cabal de este fenómeno.
} 
277, Terán, 2008, p. 11; Palti, 2014, p. 12; LaCapra, 1998, pp. 240-241; Skinner, 2007, p. 113). ${ }^{4}$

La historia intelectual busca reconstruir los campos donde se generaron las ideas y el choque producido con otras posturas de la época estudiada, logrando, además, mostrar las contradicciones y continuidades que pudo llegar a establecer un autor, descomponiendo esas obras desde diferentes vertientes y reconociendo la historicidad en las ideas sin detenerse en la mera descripción superficial de aquellas. No solo guarda un carácter técnico distinto al utilizado por la historia de las ideas, sino, además, una base material diferente (Grafton, 2007, p. 145). Es por ello que seguiremos los preceptos clásicos de la historia intelectual, analizando la forma en que Gálvez llevó adelante su creatividad y la forma en que los historiadores nos posicionamos frente a ese trabajo; cómo viajaron, circularon y se generaron sus pensamientos, considerando los ambientes intelectuales en los que se movía, las relaciones sociales que mantenía, etcétera.

Para el estudio también se torna necesario considerar a algunos autores que han estudiado los diarios y sus respectivas facetas, pues la obra de Gálvez fue presentada bajo ese formato. En principio, el diario de escritor, que vio su origen en torno al 1800, surgió en un contexto histórico signado por la "exaltación del sentimiento", la "moda de las confesiones" y el auge de la ciencia que hacía de la observación su principal herramienta (Gusmán, 2015, p. 1; Catelli, 1996, p. 92)..$^{5}$ Los primeros diaristas -John Locke, Henri de Saint-Simon, entre otros- buscaban comprender sus problemas espirituales, conocer al hombre, aplicando la observación a su persona, dando un lugar privilegiado al "yo". Dicha pauta fue utilizada en el género de los diarios ficcionales, una forma en la que el diarista es una persona ficticia. Según Hans Rudolf Picard, la primera novela que puede considerarse escrita en forma de diario es Le peintre de Saltzbourg (1803), de Charles Nodier. Allí, como en otras obras, el diario se utilizó como una técnica de la narración ficcional donde las formas de la novela en "primera persona -junto con las memorias y la novela epistolar-, sus propiedades fragmentariedad, incoherencia- adquirieron un status semiótico distinto: se convirtieron en elementos y medios de expresión en el seno de la estructura de una obra" (Picard, 1981, pp. 119-120).

En el siglo XX, momento en que se sucedieron fuertes cambios en la forma en que las personas percibían el mundo y la relación con sus semejantes, el diario íntimo sirvió para que los individuos analizaran su situación frente a la realidad, más allá de las también comunes funciones que se le otorgaba desde la ciencia como mecanismo para recopilar información producto de las observaciones (Girard, 1996, pp. 33-35). A su

\footnotetext{
${ }^{4}$ Respecto a la cultura, consideramos, como George Mosse (1998, p. 12), que refiere a un estado o "hábito mental que puede convertirse en una forma de vida íntimamente vinculada a los retos y a los dilemas de la sociedad contemporánea".

5 Según Luis Gusmán (2015, p. 1) y Nora Catelli (1996, p. 92) el Diario íntimo de Stendhal, que aquel comenzó en 1801, podría considerarse el primer diario de escritor, siendo, además, común que los diarios fueran con anterioridad confinados para su uso a muchos militares y sus campañas.
} 
vez, debemos destacar la falta de límites estructurales que guarda el estilo diarístico, ya que puede incluir fragmentos desordenados, efectuar de anotador, etc., aunque también la palabra de los otros no tiene muchas veces un verdadero lugar (Didier, 1996, p. 43). Al menos, aquel último punto dependerá de la finalidad buscada con su puesta en práctica. De cualquier forma, tal como Maurice Blanchot ha descripto, el diario tiene una cláusula de apariencia liviana, la cual radica en respetar el calendario. Es decir que escribir un diario significa ponerse, al menos en ciertas circunstancias, al "amparo de los días comunes", sometiéndose a la "regularidad feliz" que implica respetar (Blanchot, 1996, pp. 50 y 54).

En primer lugar, consideramos que el análisis sobre el pensamiento nacionalista de Gálvez en El diario de... debe estudiarse teniendo en cuenta los vaivenes que sufrió a lo largo del tiempo. Así lograremos obtener un panorama más completo sobre las variaciones que tuvo su manera de comprender el mundo.

En segundo lugar, consideramos que la elección del formato de "diario ficcional" habilitó el ingreso de Gálvez a una zona confesional en la cual expresaba sus sentimientos sobre el estado social de la Argentina hacia 1910, convirtiendo a El diario $d e . .$. en un manifiesto reaccionario de la época. De esa forma, el género literario permitió al autor explotar un rasgo propio -la pretensión de intimidad, el carácter confesional de las formas de "literatura del yo"- y al mismo tiempo postular un "tipo" representativo que era habilitado por la matriz realista de la obra.

\section{Las corrientes intelectuales en los primeros años del siglo $X X$}

En torno al período de entre siglos, momento en que la Argentina se caracterizó por el bienestar que prodigaba su modelo económico agroexportador, los círculos de intelectuales, que tenían cierta llegada en las decisiones políticas, indagaban sobre el futuro político que debían seguir las instituciones y las formas de representación: algunos proponían proseguir con el movimiento de democratización de la vida política y cultural, mientras que otros, atemorizados por la llegada masiva de inmigrantes y el crecimiento del movimiento obrero y sus reivindicaciones sociales, proponían poner límites a dicha democratización ante lo que consideraban que era una masa de trabajadores incapacitada para ejercer sus facultades políticas. ${ }^{6}$ Además, se sumaban los temores que suscitaban los inmigrantes entre la población debido a los cambios que podía sufrir aquello que las elites entendían que era la cultura argentina. Si bien cada intelectual guardaba su propia noción sobre las pautas que caracterizaban a los argentinos, muchos estaban de acuerdo en que la llegada de inmigrantes ponía en riesgo los incipientes valores y características nacionales que el país había logrado

\footnotetext{
${ }^{6}$ En ese sentido, las críticas de Joaquín V. González, aquellas en las que se marcaba la "ausencia de educación cívica del pueblo argentino" como factor decisivo para la degradación política, expuestas en el Juicio del Siglo (1910), son muestra de aquellos miedos que derivaron en la sanción de la Ley de Residencia (1902) y la Ley de Defensa Social (1910) (Gramuglio, 2001, p. 16; Altamirano y Sarlo, 2016, p. 155).
} 
asentar con posterioridad a la época colonial. Al lado del éxito económico, algunos observadores buscaban dejar en evidencia los distintos vicios culturales que podían llegar a corroer los valores de la República (Paya y Cárdenas, 1978, p. 15).

En las últimas décadas del siglo XIX, se había fortalecido la búsqueda de una identidad que hiciera referencia a la cultura y lograra un prototipo del sujeto nacional. Había alternativas: la línea nativista, que imaginaba un modelo argentino basado en el pasado nativo, en tanto lo reconocía como una entidad sin contaminaciones externas, y la derivatista, que postulaba la creación del argentino como producto de algún tipo de mezcla. Respecto a la última posibilidad, además, surgieron las posturas que consideraban la derivación desde la base criolla -idea para la que el tiempo colonial cobraba gran importancia- y otras propuestas derivatistas, sin cepa dominante, que imaginaban un prototipo de nacionalidad argentina basada en la mezcla sin predominio de ningún componente (Terán, 2008, pp. 226, 230).

Otro componente que formaba parte de las ideas que circulaban en torno al Centenario estaba en relación con la dicotomía existente entre las filosofías espiritualistas y las ciencias, cuya representación filosófica había sido acaparada por el positivismo. En torno al cambio de siglo, cobró trascendencia la "reacción idealista contra la ciencia", que no solo exaltaba las virtudes de entender la sociedad bajo los difusos principios espiritualistas, sino que rechazaba el "filisteísmo moral de la sociedad burguesa" (Altamirano y Sarlo, 2016, p. 156), las propuestas que asimilaban el progreso social al crecimiento material y la valorización de los individuos a partir de su riqueza, entre otras cuestiones.

Los intelectuales argentinos del Centenario, como Gálvez, que se encontraban dentro de la órbita de alcance que guardaba el modernismo literario, movimiento caracterizado por su anti positivismo, encontraban los valores unitarios y racionalistas del capitalismo representados en la figura del burgués, a quien caracterizaban por su mediocridad y por su incorregible mal gusto estético. Criticaban su conducta, aquello que consideraban que era una postura antinatural y sus valores pragmáticos, asemejándolo al nuevo rico, es decir, aquellos que carecían de linaje y que habían adquirido riqueza antes que educación y refinamiento. La exaltación de la bohemia, el arte y la poesía eran utilizadas para contrariar el "arribismo de la burguesía" y marginarse del sistema, haciendo "gala de la aristocracia espiritual para oponerla a la mesocracia del dinero" (Terán, 2008, p. 160; Yurkievich, 1976, p. 16). Extremaban una compleja estilización para denigrar la falta de refinamiento de los parvenus.

Siguiendo la crítica modernista, Gálvez consideraba que el "odio al verso" demostraba la falta de grandeza argentina: "Aquí los poetas gozan del más alto desprestigio. Si sus versos son mediocres y anodinos, tal vez el poeta consiga en relativa paz morirse de hambre (...) es el odio de las gentes razonables"' (Gálvez, 2001, pp. 174-175). En este punto, es necesario recordar que el poeta era para los modernistas un ser cuasi superior, no siempre estimado por la sociedad corrompida y materialista. De esta forma, solo era tomado en alta estima por aquellos que tenían un nivel 
espiritual privilegiado, usualmente caracterizado como aristocrático.7 Para Gálvez, dichas pautas caracterizaban el pasado de las provincias frente al presente de Buenos Aires: era el tiempo lejano, "tiempo de poesía, tiempo de señorío, en la tranquila, cálida, colonial Santa Fe", caracterizada por su "alma antigua" -espiritual- y su "aromada poesía" (Gálvez, 1912, p. 725).

No debemos dejar de lado la importancia que había ganado el modernismo en su faceta anti imperialista. Dicha postura tuvo lugar a partir del denominado Desastre del 98 o Guerra hispano-estadounidense, momento en que distintos autores relacionados con el modernismo literario, como José Enrique Rodó o Rubén Darío, configuraron una sensibilidad anti norteamericana, de gran incidencia en el mundo intelectual de finales del siglo XIX, como respuesta al avance de las pretensiones estadounidenses para controlar la región latinoamericana. Principalmente para Rodó, la sociedad estadounidense se encontraba gobernada por el utilitarismo y el bienestar material, mientras que los latinos se caracterizaban por su espiritualidad. De allí surgió su negativa a contaminar las particularidades de los latinoamericanos mediante la profundización de las relaciones culturales y políticas con los anglosajones. ${ }^{8}$

Preocupado por los acontecimientos sucedidos en Cuba hacia 1898 y por la circulación de ideas surgidas como resultado de su amistad con José Martí, Darío escribió un poema a Teodoro Roosevelt en el que reprochaba directamente su política imperialista. El autor se opuso al intervencionismo de Estados Unidos en América Latina llamando a Roosevelt "Cazador" y comparándolo con "AlejandroNabucodonosor" por su tendencia a ocupar, incluso con un bajo despliegue militar, distintos territorios (Darío, 1905, p. 11). La "América española" era para el autor la contracara de la ideología imperialista, por eso aconsejó a Norteamérica guardar prudencia, pues los latinoamericanos no estaban dispuestos a caer bajo el colonialismo de aquellos "hombres de ojos sajones y alma bárbara" (Darío, 1905, pp. 11-12).

Bajo la lógica que planteaban los modernistas, cobraron importancia las diferentes consideraciones sobre el continente americano: el hispanoamericanismo, el latinoamericanismo y el panamericanismo. ${ }^{9}$ A finales del siglo XIX, tanto el

\footnotetext{
${ }^{7}$ La postura anteriormente señalada había sido acuñada por Rubén Darío en $A z u l$, la obra que abrió una nueva época en la literatura latinoamericana. El gobernante que figuraba como actor principal en “El rey burgués" se distinguía de los reyes verdaderos por no tener en su corte a ningún poeta, característica que hizo de él un rey vulgar, más burgués que aristocrático, pues ignoraba las explicaciones de los poetas sobre el arte. Daba importancia a la aristocracia, no tanto como grupo económico, sino como reducto de las virtudes y bondades de aquellos individuos que no habían sido corrompidos por el materialismo (Mora, 1996, p. 8; Yurkievich, 1976, p. 13; Darío, 1981, pp. 40-41).

${ }^{8}$ Siguiendo los lineamientos del hispanoamericanismo, la crítica a la cultura estadounidense de Enrique Rodó encontró sustento en la falta de espiritualidad y refinamiento, denostados en favor del crecimiento industrial y material producto de su "orden mecánico" y el "desorden en todo lo que pertenece al dominio de las facultades ideales" (Rodó, 1920, pp. 115-116; Bergel, 2011, pp. 152-167).

${ }^{9}$ El término latinoamericanismo surgió en 1836 bajo las crónicas periodísticas sobre un extenso viaje que había realizado Michel Chevalier -un prominente sansimoniano francés- por Estados Unidos. Allí, sistematizó categorías étnico-culturales en donde destacaba las dos ramas, anglosajona y latina, que tenía América. Tiempo después, con las repercusiones de la obra de José Enrique Rodó y el movimiento
} 
hispanoamericanismo como el latinoamericanismo eran presentados como reacciones de confrontación contra los valores materialistas e imperialistas que proyectaban distintas naciones, como Estados Unidos, hacia la región de Latinoamérica. Sobre todo, el hispanoamericanismo -postura asociada a las naciones que habían formado parte del imperio español, surgida como una derivación de la influencia cultural de dicho país que afirmaba los valores históricos de la hispanidad- funcionó como la contrapartida del "utilitarismo anglosajón", especialmente en el contexto político signado por el avance del imperialismo norteamericano ante las últimas colonias de las que disponía España. Los hispanoamericanistas basaban sus argumentos en la cultura compartida por los países sudamericanos frente a España y destacaban al catolicismo y al hispanismo como puentes de unión entre las naciones (Zanetti, 1994, pp. 492-493; Terán, 2008, pp. 157-158 y 164-165).

En síntesis, el avance de Estados Unidos en Latinoamérica, el materialismo y la exagerada opulencia en las costumbres sociales, al igual que la llegada de miles de inmigrantes al país, entre otras cuestiones, fueron interpretadas por distintos intelectuales como síntomas de una declinación moral generalizada. El incipiente proceso industrializador, el crecimiento de las ciudades y las nuevas pautas y costumbres sociales generaron en los individuos la sensación de estar viviendo una época caótica en la que los valores tradicionales y los ritmos de vida estaban siendo modificados. Todas estas cuestiones generaron temores y ansiedades en aquellos que no podían adaptarse a los rápidos cambios culturales de principios de siglo $\mathrm{XX}$, dando lugar a escritos que buscaban brindar diagnósticos sobre la situación argentina y distintas soluciones para poder resolver aquellos problemas -no siempre tan trascendentales- que preocupaban a la intelectualidad de la época.

\section{El diario de Gabriel Quiroga: síntoma de un contexto de época}

Hacia 1910, Gálvez había contraído matrimonio con Delfina Bunge para luego instalarse en una propiedad en las afueras de Buenos Aires. Allí, escribió El diario de Gabriel Quiroga, definido por el autor como "un libro nacionalista y agresivo, irónico y mordaz" que mostraba los apuntes de Gabriel Quiroga, un personaje de su invención cuyo nombre era el de un "lejano antepasado" (Gálvez, 2002, p. 333). Si bien pasó casi inadvertido al momento de su publicación, fue un texto ineludible para muchos intelectuales de la década de 1930 -como los hermanos Julio y Rodolfo Irazusta, Ernesto Palacio, César Pico y Raúl Scalabrini Ortiz-, que recuperaron algunos de los tópicos propuestos en El diario de..., al igual que las ideas de Leopoldo Lugones, habiendo sido Gálvez "el más reiterado objeto de hostilidad de los jóvenes de la nueva sensibilidad" (Devoto, 2002, p. 155).

modernista, fue que el término transmutó como una reacción contra el expansionismo norteamericano y la representación de una entidad étnico-cultural (Ardao, 1986, p. 160).

Anuario de la Escuela de Historia Virtual - Año 11 - Nº 17 - 2020: pp. 57-78. ISSN: 1853-7049 
Nuestro autor presentó el escrito mediante el formato de un diario íntimo ficcional. Según Oscar Terán (2008, p. 162), era una alternativa utilizada por el artista modernista: "recluirse en el propio yo, en la pura subjetividad del artista modernista, separándose de una realidad, recluyéndose en una sensibilidad estética exquisita como la única alternativa frente al materialismo y la mediocridad de la vida moderna". En ese sentido, el formato de escritura puede ser pensado como una manera de remediar las angustias de una época mediante la interiorización de los problemas -algo que caracterizaba el espacio de la intimidad moderna- para reconquistar y reconstruir aquellos aspectos de la cotidianeidad que se consideraban perdidos.

Gálvez utilizó dicho formato para realizar un ensayo crítico que señalara los "vicios y defectos" argentinos y homenajeara a la Patria diciendo un "poco de verdad sobre ella misma": representaba un "libro político" que, siguiendo la sensibilidad modernista, buscaba destacar todas las expresiones de la vida argentina (Gálvez, 2001, pp. 73-74, 80; Gramuglio, 2001, p. 47; Quijada, 1985, pp. 24-26). El autor mostró su manera de ver la vida tratando de invocar ideas por él consideradas en peligro y buscando cambiar una cosmovisión -liberal, materialista y cosmopolita- que denostaba, logrando generar una tensión en la obra entre su propia subjetividad y la voluntad de intervenir en la sociedad.

Los intelectuales de principios del siglo $X X$, sin ser necesariamente conscientes de los cambios sociales que estaban viviendo, sufrían todas sus consecuencias, viendo tambalear sus posturas morales y valores culturales arraigados, razón por la que el diario se constituyó en una forma de encontrar bases para el nuevo equilibrio personal, es decir, un espacio de reflexión individual que permitía meditar sobre dicha época y ordenar las distintas impresiones que generaba la cotidianeidad. Los individuos, ante el rápido crecimiento de la población en Argentina, se veían perdidos frente a la masa indistinta, logrando frustrarse por la nueva naturaleza de las relaciones sociales: “ya no tienen relaciones íntimas con los demás y no dejan de cruzarse con seres anónimos como él" (Girard, 1996, p. 35). Si bien alcanzaron un inusitado nivel de vida por las nuevas tecnologías, se profundizó el sentimiento de inseguridad por definir el lugar social de los individuos ante sus semejantes, razón por la que el diario íntimo, dada su prevalencia del yo, se volvió trascendental para adaptarse a las nuevas circunstancias.

En consonancia con los anteriores postulados, no sería errado considerar El diario de... bajo los términos en que Blanchot (1996, pp. 50-51) ha descripto dicho género: "es una manera cómoda de escapar al silencio", para "recordarse a sí mismo", en donde un autor se "cuida del olvido y de la desesperación" para "alzar la vida nula hasta la bella sorpresa del arte", siguiendo una "empresa de salvación" en la que se rescata su "pequeño yo".

Era común que muchos individuos de origen provincial, como Gálvez, llevaran adelante un diario debido a la tranquila vida, introspectiva y vacía, que podían transitar en el interior del país. El formato de diario funcionó en la obra como una forma de interrogar al mundo y la posición tomada frente a los cambios de la sociedad 
de mercado, aquella que hacía proliferar los sentimientos de soledad en las personas que se percibían viviendo en una multitud bajo el anonimato, siendo Gabriel Quiroga, aquel que era presentado en la "Introducción" como un amigo del editor, un alter-ego de Gálvez. Su condición, destacaba, no lo responsabiliza de las ideas de Quiroga. Sin embargo, dicha postura era consecuencia de la cautela adquirida ante la situación precaria del escritor en el campo literario hacia principios del siglo XX (Gramuglio, 2001, pp. 45, 51; Gálvez, 2001, p. 76; Camurati, 2006, p. 131; Pérez, 2006, p. 2).

En sus Recuerdos de la vida literaria (I), Gálvez aclaró que, al momento de escribir El diario de..., los temas allí tratados tenían "puntos de contacto", pero que no guardaban una cohesión total: "el problema consistía en reunir los temas afines para hacer desaparecer las referencias que daban sensación de lo repetido" (Gálvez, 2002, p. 334). Es probable que acudiera al formato de diario ficcional para conseguir aquella cohesión que buscaba dar a su relato. Como mencionamos anteriormente, el diario de escritores tiene un formato relativamente libre, cuya únicamente restringido por la cronología del tiempo: "no conoce reglas ni verdaderos límites, el diario puede abrirse a cualquier cosa" (Didier, 1996, p. 39). Así, el género permitió a Gálvez dar lugar a las repeticiones, al desorden en las ideas transmitidas y las constantes autorreferencias. Es decir, otorgaba cierta independencia en la redacción de su obra que, posiblemente, no hubiese logrado utilizando el formato más tradicional de una novela para presentar su pensamiento. Sin embargo, a pesar de las constantes repeticiones temáticas de las cuales Gálvez dio cuenta, El diario de... no responde en su totalidad a las pautas de un diario personal original, pues, al buscar ser un escrito comercial, fue víctima de distintos cortes y correcciones que eran necesarios realizar para su posterior edición.

Partiendo del formato anteriormente mencionado, el autor dejó formadas sus impresiones bajo diferentes fechas, sin un orden esquemático, sino circunstancial, que abarcaba desde el 4 de enero de 1907 al 25 de mayo de 1910. Gabriel Quiroga habría comenzado a escribir su diario al cumplir los veintidós años ante una crisis de "depresión espiritual" en su búsqueda por la "perfección moral": las explicaciones materialistas y científicas no lo satisfacían para dar respuesta a los conflictos de su vida (Gálvez, 2001, pp. 62-63).

El público que dio recepción a las nociones expresadas en la obra de Gálvez estaba conformado por las antiguas elites que guardaban una idea de nación argentina asociada a la cultura del gaucho, rural, con influencia hispánica y católica. Aquellos eran los mismos sectores que, al igual que el autor, se consideraban amenazados por las ideas y pensamientos que traían los inmigrantes en un contexto de época signado por la llegada de extranjeros hacia la Argentina. El diario de... advertía sobre el peligro que conllevaba dicho proceso inmigratorio, aquel que, consideraba, había surgido por sostener el afán de crecimiento capitalista -la necesidad de mano de obra para la producción- el enriquecimiento y el materialismo.

El autor consideraba que aquellos inmigrantes -enquistados en las ciudadesestaban destruyendo la cultura nacional. Eran presentados como un peligro social que 
debía ser neutralizado y anegado en la vastedad del alma nacional. Para Gálvez, los extranjeros levantaban fortunas que "casi siempre llevan con ellos a Europa", a la vez que se convertían en advenedizos solo preocupados por su riqueza: "el inmigrante no puede ser sino superficial (...) para el no existen más valores que los valores materiales", eran "gente hambrienta" y desmoralizada que tenían la "superstición del dinero" (Gálvez, 2001, pp. 14, 107, 143, 171).

Respecto a los inmigrantes, en obras posteriores, Gálvez realizó un estereotipo sobre los judíos al considerarlos los exponentes de todos los aspectos negativos que tenía la sociedad moderna. Considerando al catolicismo como parte de la cultura argentina y al espiritualismo la expresión más acabada del ideal cultural a alcanzar por una sociedad civilizada, el judío cumplía la imagen negativa de ser un ente corruptor de los valores argentinos -un visitante extranjero indeseado por la tradicional sociedad-pues, para el autor, no creían en los pecados ni tenían remordimiento alguno ante sus actos. Bajo dicho esquema es que los judíos fueron presentados como una raza de estafadores, usureros, comerciantes inescrupulosos, que se aprovechaban de las desdichas ajenas para hacer negocios con los más desafortunados (Gálvez, 1917, pp. 91, 153 y 183; Gálvez, 1938, p. 66).

Formulado como estaba en el diario el rechazo a los extranjeros y la apelación al conjunto de la sociedad para luchar contra sus ideas, las que eran presentadas sin fisuras y de forma unánime, Gálvez produjo una tensión en el formato entre el registro de la primera persona, una obvia característica de los diarios y su registro cotidiano, y la primera persona del plural (nosotros), ya fuese aquella inclusiva o exclusiva. Dicha tensión puede pensarse además como un programa ideológico: la elección de la primera persona del plural, por ejemplo, puede indicar también la reticencia o confianza respecto de la propia formulación.

Las consideraciones sobre la influencia española en la cultura argentina y el desgaste que aquella había recibido por la influencia de inmigrantes fueron esenciales en la idea de nación mostrada por el autor en El diario de... Tanto en El Solar de la Raza (1913) como en El diario de... destacó la historia del linaje criollo y la hispanidad en la Argentina, aspectos que estaban encuadrados bajo lo que consideraba era la tradición nacional. ${ }^{10}$ Siguiendo esa lógica es que Gálvez solo pedía a los extranjeros "el olvido de todas las patrias", ya que de esa forma, bajo la "libertad y la democracia", una "raza predestinada" tendría "destinos magníficos" (Gálvez, 2001, pp. 58, 85-86, 94-96, 107; Gálvez, 1913, pp. 19-21, 27, 42-49).

\footnotetext{
10 En el pensamiento de Gálvez el alma nacional podía ser recuperada, pues en España, afirmaba, la conquista árabe del siglo VIII no había modificado su cultura. Por el contrario, dicho país había mantenido el producto de la influencia romana. De esta forma, los inmigrantes no tenían posibilidad -ni derecho- a cambiar las supuestas costumbres arraigadas en la Argentina. Como en España -cuya mezcla con el elemento arábigo no tenía "demasiada importancia", siendo un pueblo sin "personalidad ni carácter", pues dicha cultura no representaba a la cultura ibérica ni siquiera en la literatura-, los inmigrantes en Argentina no debían destacarse ni alterar la vieja imagen cultural criolla (Gálvez, 1913, pp. 163-173, 194-195).
} 
La impronta española era para él necesaria, pues "lejos de descaracterizarnos, como ciertas influencias exóticas", nos ayudaba a afirmar "nuestra índole americana y argentina", aunque no explicó de qué manera esa ayuda era posible (Gálvez, 1913, p. 21). Consideraba que al haber "vivido en Dios durante siglos", bajo sus costumbres, España todavía conservaba el estilo de vida cristiano antiguo, razón por la que su cercanía con Argentina cobraba mucha trascendencia (Gálvez, 1913, p. 28). Para entender el alma de la raza el autor creía necesario conocer su solar, es decir el alma española.

España era la "Nación católica por excelencia", afirmaba, cuestión que hacía de los castellanos seres sobrios que no se desvivían por los "placeres materiales", diferentes de los ingleses que ostentaban una "irritante crueldad moral" y difamaban la cultura española (Gálvez, 1913, pp. 29, 49, 42, 46). De esa forma, los males materialistas de la sociedad, incluidos el afán por el dinero, producto del liberalismo, habrían surgido como consecuencia del cosmopolitanismo porteño y el abandono de los tradicionales valores hispánicos que Gálvez defendía.

El autor hablaba de las exigencias de su época, aquellas que requerían recuperar a la raza argentina -descripción en clave levemente biologicista que combinaba con su postura modernista-, sus características hispánicas y católicas, ante el peligro de la inmigración europea. Defendía al catolicismo como un método para luchar contra los males que el movimiento trasatlántico de individuos había traído aparejado, pues dicha religión, afirmaba, servía para desarrollar aquella faceta espiritual de la cual carecían los argentinos. En ese sentido, Gálvez fue quien mejor reunió los rasgos "para una contraposición convencional entre positivismo-anti positivismo y para simbolizar la emergencia de una primera generación nacionalista" (Devoto, 2002, pp. 42-43).

En El diario de..., mostró su faceta nacionalista, basada en pensamientos sutiles y metafísicos, contrarios al positivismo en boga a principios de siglo $\mathrm{XX}$, que no dejaba de lado las preocupaciones sobre los cambios culturales y el materialismo, inquietudes que encontraban respuesta en su defensa del catolicismo y la espiritualidad. Mientras denostaba al liberalismo individualista, cuyo exponente encontraba en las cosmopolitas ciudades que hacían "triste la vida", la religión le ofrecía consuelo eterno. El camino para no caer en la desgracia era, entonces, dejar de lado aquellos ideales -la búsqueda de riqueza y el materialismo- para recuperar "nuestra alma colectiva", la cual había sido sembrada por la influencia española-católica (Gálvez, 2001, pp. 85-87, 100, 114-115).

En su búsqueda por rescatar la espiritualidad, cobró mucha importancia el acercamiento que logró Delfina Bunge entre Gálvez y el catolicismo. A lo largo de su carrera intelectual, pudimos observar cómo la fe católica servía para encauzar las posturas irracionalistas del autor y otorgarle un modelo de vida que lo protegiera del materialismo, arraigado en lo que consideraba era una de las facetas más importantes de la cultura nacional (Gálvez, 1938, pp. 85-86, 99-100; Gálvez, 1913, pp. 19-21, 27; Paya y Cárdenas, 1978, p. 25). 
El catolicismo y la figura de Dios eran asociados por Gálvez a la idea de belleza. ${ }^{11}$ Consideraba que, siendo su búsqueda -la descripción y representación- un estilo de vida, la belleza debía buscarse en el alma, a través de lo espiritual, pues estaba directamente asociada a la idea del amor, siendo necesario acercarse a Dios, pues representaba el amor absoluto, "la armonía y compenetración de todas las cosas" (Gálvez, 1928, pp. 77, 89). De esta forma, si se fracasaba a nivel espiritual y religioso, aspectos estrechamente ligados a la belleza, tendría implicancias a nivel amoroso, fraternal y personal. Como consecuencia, las personas recaerían en una vida vacía, encantadora en un comienzo, pero desagradable al final de cuentas.

Siguiendo las posturas del decadentismo, Gálvez criticaba la idiosincrasia cosmopolita que Buenos Aires, creía, buscaba impartir en el alma de la patria vieja, aquella que encontraba en los pueblos del interior y las comarcas litorales. Mientras que la capital argentina mostraba una "falta absoluta de sentimiento estético", producto de la supresión de su "porvenir espiritual" y sus "bellezas prestadas", las ciudades provinciales tenían para el autor una fisionomía propia que no había sido alcanzada por los vicios del mercado y las influencias estéticas externas, razón que hacía de ellas las verdaderas representantes del sentir criollo (Gálvez, 2001, pp. 91-94). ${ }^{12}$

El personaje Gabriel Quiroga fue representado como un "patriota" que destacaba el "espíritu de las provincias" para la "reconquista espiritual del país" (Gálvez, 2001, pp. 75, 86, 88, 143 y 148). Postulaba recuperar el "alma argentina", oculta tras el materialismo escéptico, cosmopolita y sin personalidad de Buenos Aires, mediante la exaltación de las tradiciones, las cuales eran conservadas en la cultura provincial: allí radicaba la hispanidad criolla que serviría para nacionalizar al extranjero (Gálvez, 1917, pp. 91, 153, 183; Gálvez, 2001, pp. 90-91, 94, 98, 140).

Siguiendo el anterior punto es que cobra importancia el análisis nacionalista sobre el pasado argentino realizado por Gálvez en El diario de... Si bien la obra surgió con anterioridad al nacimiento del revisionismo histórico, ${ }^{13}$ producto de la crisis argentina

\footnotetext{
${ }^{11}$ El amor a la belleza constituyó un rasgo decisivo para el modernismo: lo bello era relacionado con lo bueno. Los cuentos de $A z u l$ de Rubén Darío ejemplificaban la búsqueda de la Belleza como unida a un sentido del Bien, también asociado a la justicia (Mora, 1996, pp. 18-21).

${ }^{12}$ Autores como Camurati (2006, p. 134) han propuesto que la "organización en compartimientos estancos de la sociedad argentina" era la base sobre la cual Gálvez estructuró los "fundamentos de la nueva nación argentina", cuando, como hemos argumentado, el autor buscaba rescatar lo que reconocía que eran antiguos valores arraigados en las provincias para luchar contra una nueva idea de nación cultural surgida como resultado de la inmigración masiva. El problema no radicaba en la acumulación de dinero, sino en la cultura que expresaban las personas, en especial los que se enriquecían rápidamente.

${ }^{13}$ Los autores revisionistas utilizaban la historia como una herramienta que servía para establecer el momento en que se había abandonado el correcto camino de grandeza de la Argentina por otro, caracterizado mediante el liberalismo y el materialismo, que habría corrompido a la sociedad, logrando su decadencia. No perseguían el afán de construir un simple relato, sino que buscaban apelar a la memoria de la sociedad, mediante distintos discursos que guardaban una función ejemplificadora, para movilizar políticamente a la población (Palacio, 1960, pp. 14-15). De allí partían los revisionistas para afirmar que en el país existía una "historia oficial", un relato elaborado por los vencedores -la "oligarquía" y los "enemigos del pueblo argentino", quienes pretendían que una "clase 'educada y racional' fuera todo el país" (Rosa, 1968, pp. 27-30, 34-35; Chiaramonte, 2013, p. 260)-, y otra historia verdadera, que además de
} 
de 1930 y el colapso del modelo agro-exportador, el autor anticipó allí muchos de los tópicos que luego retomó desde su postura decididamente revisionista, adoptada en torno a 1935.

En El diario de... Gálvez ya hablaba de los unitarios como "seres artificiosos y decorativos que eran más europeos que argentinos". Tal como destacaron los revisionistas con posterioridad, caracterizaba a los defensores del unitarismo por sus “principios importados" y liberales (Gálvez, 2001, pp. 135-136). Aquellos, afirmó, tenían la manía civilizadora y desconocedora del ambiente; buscaban implantar las mejores instituciones extranjeras en Argentina para imitar a los países europeos. ${ }^{14}$ En su pensamiento, el unitarismo representaba al espíritu del Viejo Continente, razón por la que se creía capacitado para despreciar la cultura criolla y las costumbres gauchas. Además, para Gálvez, los unitarios detestaban a España y carecían de verdadero patriotismo, porque no sentían el alma nacional. Por el contrario, el federalismo, ligado a la cultura del interior, era "criollo", "sencillo y democrático, conservador y proteccionista” (Gálvez, 2001, pp. 124, 194-195). Más allá de la importación de ideas, no consideraba que los unitarios fuesen democráticos, solo a excepción de aquellos que no conservaban su espíritu, como Domingo F. Sarmiento y Bartolomé Mitre, figuras que el autor usualmente destacaba hacia principios del siglo XX.15

Es probable que la anterior exaltación del federalismo y la cultura provincial a través de la historia nacional haya surgido, entre otras cuestiones, mediante la

desmentir a la historia oficial, servía como fundamento en la lucha política contra el imperialismo. De todas formas, tal como afirmó Alejandro Cattaruzza, es adecuado considerarlos como un grupo de intelectuales que procuró intervenir en "la amplia zona de encuentro entre el mundo cultural, incluyendo en él a las instituciones historiográficas y la política". Hubo distintos debates sobre la génesis del revisionismo. Sin embargo, desde la perspectiva de este trabajo consideramos anacrónico extender la categoría de revisionistas a distintos autores del siglo XIX (como Ernesto Quesada, David Peña y Adolfo Saldías, entre otros), ya que, si bien eran contrarios al relato mitrista, ligado a la denominada "historia oficial", no se definían como tales. Sus estudios se encontraban cerca de la metodología de investigación utilizada por Mitre y pocas características e ideas similares guardaban los intelectuales decimonónicos con los revisionistas de la década de 1930. Además, el momento histórico en que realizaron sus relatos era completamente distinto. Mientras que los revisionistas, en su mayoría también decididos nacionalistas, buscaban desentrañar la defección política y la influencia política inglesa en el país, los autores decimonónicos, mayormente defensores del liberalismo, estaban más abocados a la revalorización del federalismo mediante figuras que consideraban olvidadas por la historiografía mitrista. Es común al rastrear la génesis de distintos movimientos que se incurra en anacronismos, pues, a partir de ciertas similitudes terminológicas, los historiadores creen descubrir las posturas compartidas y sostenidas por dos autores respecto a un tema particular, cuando, en realidad, las similitudes en sus ideas no son un argumento suficiente para identificarlos como partícipes de un mismo movimiento cultural (Cattaruzza y Eujanián, 2003, pp. 145-146; Kroeber, 1964, pp. 45-52; Quattrocchi-Woisson, 1995, pp. 34-35; Halperín Donghi, 2005, pp. 14-20; Devoto y Pagano, 2009, pp. 221-255; Buchbinder, 2008, p. 178).

${ }^{14}$ Con posterioridad, los hermanos Irazusta también criticaron el afán de Bernardino Rivadavia por crear "instituciones perfectas" dejando de lado la conquista de territorios. Al mismo tiempo, consideraban que Rivadavia, siendo representante de la "oligarquía", seguía al liberalismo en el terreno espiritual y económico, a la vez que abandonaba a su suerte a las provincias del interior. En una óptica similar fue dirigida la crítica de Raúl Scalabrini Ortiz hacia 1935 (Irazusta e Irazusta, 1982, pp. 140, 142; Scalabrini Ortiz, 1940, p. 124).

${ }^{15}$ Incluso, la obra estaba dedicada a Bartolomé Mitre y Domingo F. Sarmiento, pues habían expresado “el alma de la patria vieja" (Gálvez, 2001, pp. 59, 100, 107, 114-116).

Anuario de la Escuela de Historia Virtual - Año 11 - N 17 - 2020: pp. 57-78. ISSN: 1853-7049 
circulación de ideas producto de su relación con David Peña. ${ }^{16}$ Nacido en 1862 y de origen rosarino, Peña fue profesor suplente de Historia Argentina en la Facultad de Filosofía y Letras de la UBA. Siendo su obra más importante Juan Facundo Quiroga (1906), la cual reúne sus conferencias dictadas en 1903, utilizó allí gran cantidad de fuentes primarias para darle el mayor carácter académico posible a su texto (Devoto y Pagano, 2010, p. 204). En su Juan Facundo Quiroga, destacó que los caudillos no eran jefes que detentaban un dominio privado basado en sus riquezas y poder social, sino una elite que buscaba darse una organización gubernamental con el fin último de crear un poder supraprovincial. Frente a la postura de Sarmiento, quien describía a la política de la época como salvaje y bárbara, Peña restituía el grado de legalidad manejado por los líderes provinciales de la sociedad confederacional y vindicaba gran parte de la cultura caudillesca y del interior del país (Peña, 1906, pp. 9-12; Rubio García y Rubio García, 2016, pp. 12-17).

Gálvez escribió una reseña sobre el escrito de Peña en donde dejó en evidencia su descreimiento sobre la Historia, una óptica similar con la que observaba su época. En el caso de Quiroga, para el autor servía para "comprender el alma del personaje" analizado, aunque dudaba de la importancia que pudiesen cobrar los documentos, tradiciones y recuerdos en dicha tarea (Gálvez, 1907, p. 184). En la reseña, adscribió a las posturas de Peña, ya que afirmó ser un defensor de la figura de Quiroga -por quien se había sentido impresionado cuando era niño- describiéndolo, siguiendo al rosarino, como "el símbolo de una raza", magnánimo y generoso, alguien que "sabía de buenos sentimientos y grandes acciones" (Gálvez, 1907, p. 185).

De cualquier forma, aquellos valores perdidos y las críticas al pasado político argentino encontraban respuesta mediante el nacionalismo, cosmovisión que el autor no dudó en definir en El diario de..., pero que, de todas formas, como sucedió con la mayoría de los nacionalistas, en especial en torno a 1935, fue cambiando en su ideario a lo largo de los años. ${ }^{17}$ Hacia 1910 escribió:

El nacionalismo persigue el afianzamiento del espíritu nacional, la conservación de las tradiciones, la emoción del pasado, el amor de nuestra historia, a nuestros paisajes, a nuestras costumbres, a nuestros escritores, a nuestro arte. El nacionalismo anhela la grandeza espiritual del país sin despreciar por ello los intereses materiales (...) el nacionalismo es la más alta expresión del amor a la patria en los actuales momentos de nuestra civilización (Gálvez, 2001, pp. 200-201).

\footnotetext{
${ }^{16}$ José Gálvez, tío de Manuel y Gobernador de Santa Fe (1886-1890), creó un diario, Nueva Época (1886), en el cual realizó sus primeras armas literarias su sobrino, siendo, además, dirigido por David Peña, amigo de muchos escritores de la revista IDEAS y colaborador, al igual que Manuel.

${ }_{17} \mathrm{Su}$ idea de nacionalismo fue reconfigurada en la década de 1930. En su papel de escritor colaborador para el diario Reconquista (1939), Gálvez destacó la unión que entre un gran número de intelectuales -que muchas veces se habían encontrado en veredas opuestas- había logrado llevar a adelante el periódico neutralista en torno a la Segunda Guerra Mundial. Los anti imperialistas del periódico -Rodolfo Irazusta, Raúl Scalabrini Ortiz, Ernesto Palacio, entre otros- compartieron un objetivo común sobre la "independencia económica y espiritual", funcionando Reconquista como una institución aglutinadora de pensadores y formadora de proyectos políticos (Gálvez, 1939, pp. 1-2).
}

Anuario de la Escuela de Historia Virtual - Año 11 - Nº 17 - 2020: pp. 57-78. ISSN: 1853-7049 
Siguiendo las anteriores ideas es que Gálvez pensaba en diferentes métodos mediante los cuales pretendía incentivar el patriotismo de manera rápida. La guerra, entonces, se convirtió en una forma eficaz para acrecentar los sentimientos nacionalistas agresivos, de corte militar, en el ciudadano corriente. Además, serviría, según consideraba, para que distintos actores poco respetables socialmente fueran transformados en individuos honestos. Tal como destacó en El diario de..., mediante el espiritualismo militar y la guerra con el Brasil se podría quitar las bajezas humanas que tanto le molestaban. Estas ideas iban en consonancia con el posterior acercamiento de Gálvez hacia algunas de las posturas del fascismo: se sentía cautivado por la "severa moral fascista", aquella que, según creía, podría quitar los "vicios" impartidos por la economía de mercado (Gálvez, 2001, p. 101; 2002, pp. 694-695). Era común que hacia la década de 1920 muchos intelectuales, entre ellos Gálvez y los hermanos Irazusta, buscaran en el Ejército y la Iglesia mecanismos para luchar contra la democracia y la corrupción generalizada que, creían, había instaurado el liberalismo. El objetivo era desarrollar un Estado corporativista que se desentendiera de los usuales mecanismos políticos y sus representantes.

Podemos encontrarnos con las anteriores posturas en ciertos párrafos de $E l$ diario de..., claramente enquistados en las ideas de Maurice Barrès -un escritor francés de finales del siglo XIX que inspiró a muchísimos intelectuales nacionalistas-, meditados para celebrar la violencia y condenar al materialismo social como un mal a erradicar de la nación. De esta forma es que se explica el pensamiento de Gálvez: encontraba la salvación de la República Argentina en la guerra con el Brasil. Una contienda militar, afirmaba, haría que los pueblos se conociesen, reuniría a los argentinos en un ideal común y despertaría en el país entero el sentimiento de la nacionalidad. Especialmente, creía que remplazaría "en nuestras almas y en nuestros corazones a la tendencia utilitarista, a los sentimientos materialistas", logrando despertar, bajo la "conmoción patriótica", "el genio poético de la raza" (Gálvez, 2001, pp. 101-102; Grinchpun, 2011, pp. 191-224). No era trascendental la victoria o la derrota, pues, para aquel, de todas formas, el país habría de tener muchos recuerdos heroicos surgidos en las batallas.

En definitiva, como Gálvez destacó en toda la obra, su principal preocupación era despertar, de una forma $u$ otra, la espiritualidad en las personas, teniendo en cuenta que, además, para él dicha meta se desvanecía con el correr del tiempo ante las nuevas formas de entender la vida que adoptaba la sociedad, aquellas que se distanciaban de las características provinciales que anhelaba rescatar del olvido. En ese punto, probablemente, haya cobrado importancia el formato de diario para presentar su escrito: el género era atinado para expresar los pliegues sentimentales íntimos y servía para lograr configurar un colectivo argentino que luchara para recuperar la supuesta nacionalidad perdida. 


\section{Conclusión}

El diario de Gabriel Quiroga fue una obra que alcanzó poco éxito comercial. Sin embargo, fue trascendental para el imaginario y las construcciones que surgieron en la década de 1920 y 1930 entre los grupos que defendían distintas posturas nacionalistas. En ese sentido, el relato de Gálvez se convirtió en un punto de referencia -positivo y negativo- importante para los intelectuales -como Raúl Scalabrini Ortiz, los hermanos Julio y Rodolfo Irazusta y Juan E. Carulla- que partieron de allí para transmutar sus ideas en un espectro ideológico que abarcaba posturas de toda índole. Debemos considerar la trascendencia que cobraron los postulados nacionalistas en los primeros años del siglo $\mathrm{XX}$, no solo como respuesta a la apertura inmigratoria, económica y política que incentivaron los gobiernos que se sucedieron desde 1880 en Argentina, sino también como un antecedente en los argumentos que posteriormente tuvieron importancia ante la crisis que vivió el país en torno a 1930.

Es probable que Gálvez eligiera el formato de diario en su obra para establecer cierta cercanía con su público, dejar en evidencia su propio yo y lograr una emotividadafinidad en sus lectores que quizá no hubiese podido conseguir utilizando otros géneros. Sin embargo, no debemos olvidar las propias complicaciones que el autor describió al momento de realizar la obra, aquellas que posiblemente lo hayan inducido a elegir ese género. Aquel daba cierta cohesión a su desordenado escrito y permitía, sin alejarse de los cánones de aceptación intelectual y literaria, las constantes repeticiones en sus ideas. Al fin y al cabo, El diario de... era un conjunto de declaraciones personales que Gálvez expresó utilizando un alter-ego. La obra no relataba una historia, sino que describía críticamente el estado cultural y social de la época bajo la mirada de Gabriel Quiroga, un representante de la elite que percibía su inutilidad para cambiar el rumbo -imparable- de la modernidad.

Como ha sucedido con muchos intelectuales, la producción de los escritos realizados por Gálvez estuvo atravesada por las pretensiones y cambios que esperaba realizar para la Argentina. Así, buscó en el pasado determinar aquellos desvíos sociales y culturales que se habían sucedido, terminando por afirmar desde sus obras el abandono de lo que él entendía que era la cultura argentina. No solo acudió a la historia para realizar una crítica política y económica que iba en consonancia con las ideas anti imperialistas vigentes a principios del siglo $X X$, sino también para encontrar una herramienta efectiva que determinara las supuestas características culturales que los argentinos habían tenido hasta mediados del siglo XIX, momento en que los movimientos migratorios hacia el país, con su consecuente flujo de pautas culturales, comenzaron a cobrar mayor importancia.

Para el autor, muchos de los problemas que habían acontecido en el país se debían al avance del capitalismo y el liberalismo como sistemas políticos y económicos, regímenes que, consideraba, eran ajenos a las tradiciones argentinas. Como resultado, su relato histórico se caracterizó por abordar el análisis de distintas figuras del siglo 
XIX con las que ejemplificaba las características que debían guardar aquellos políticos que buscaba realzar socialmente, a la par que criticaba y denostaba mediante los contraejemplos a distintas figuras de su contexto de época que reprobaba políticamente por sus posturas eurocentristas.

De cualquier forma, como brevemente esbozamos al principio del escrito, el relato de Gálvez tuvo la virtud de llegar a un público que, ávido por comprender las problemáticas sociales argentinas, adhirió a su relato. Con posterioridad a la publicación de El diario de..., mediante las biografías de personajes y las novelas históricas, el autor encontró una faceta comercial que había quedado vacante en el mercado literario, ganando un lugar importante entre los literatos que hicieron de la historia argentina una parte importante de su biografía.

\section{Referencias bibliográficas:}

Altamirano, C. (2005). Para un programa de historia intelectual y otros ensayos. Buenos Aires: Siglo XXI.

Altamirano, C. (2013). Intelectuales. Notas de investigación sobre una tribu inquieta. Buenos Aires: Siglo XXI.

Altamirano, C. y Sarlo, S. (2016). Ensayos argentinos. De Sarmiento a la vanguardia. Buenos Aires: Siglo XXI.

Ardao, A. (1986). Panamericanismo y latinoamericanismo. En L. Zea (Ed.), América Latina en sus ideas (pp. 157-171). México: Siglo XXI.

Bergel, M. (2017). El anti-antinorteamericanismo en América Latina (1898-1930). Apuntes para una historia intelectual. Nueva Sociedad, (46), 2-17.

Buchbinder, P. (2008). La Nación desde las provincias: las historiografías provinciales argentinas entre dos Centenarios. Anuario del Centro de Estudios Históricos "Prof. Carlos S. A. Segreti", (8), 163-182

Burke, P. (2017). ¿Qué es la historia del conocimiento? Cómo la información dispersa se ha convertido en saber consolidado a lo largo de la historia. Buenos Aires: Siglo XXI.

Camurati, F. (2006). Manuel Gálvez y la construcción de un imaginario nacional a través de la oposición campo-ciudad. Caravelle, (87), 129-145.

Catelli, N. (1996). El diario íntimo: una posición femenina. Revista de Occidente, (182183), 87-99.

Cattaruzza, A. y Eujanián, A. (2003). Políticas de la historia: Argentina 1860-1960. Buenos Aires: Alianza.

Chiaramonte, J. C. (2013). Usos políticos de la historia. Lenguaje de clases y revisionismo histórico. Buenos Aires: Sudamericana.

Clementi, H. (2001). Manuel Gálvez atravesando nuestra historia. Remedios de Escalada de San Martín: Leviatán.

Darío, R. (1905). A Roosevelt. Recuperado de www.poderjudicial.gob.ni/centenariodario/pdf/cantos-de-vida-y-esperanza.pdf (Fecha de consulta 20/10/2018). 
Darío, R. (1981). Azul... México: Editores mexicanos unidos S.A./Ediasa Libreros.

Didier, B. (1996). El diario ¿forma abierta? Revista de Occidente, (182-183), 39-45.

Blanchot, M. (1996). El diario íntimo: una posición femenina. Revista de Occidente, (182183), 47-55.

Devoto, F. (2002). Nacionalismo, fascismo y tradicionalismo en la Argentina. Una historia. Buenos Aires: Siglo XXI.

Devoto, F. y Pagano, N. (2010). Historia de la historiografía argentina. Buenos Aires: Sudamericana.

Gálvez, M. (1907). Facundo. Revista de Derecho, Historia y Letras, (26), 184-188.

Gálvez, M. (1912). Viejos recuerdos. Mundial Magazine, (12), diciembre, 752.

Gálvez, M. (1913). El solar de la raza. Buenos Aires: La Facultad.

Gálvez, M. (1917). El mal metafísico. Buenos Aires: Nosotros.

Gálvez, M. (1928). El hombre de los ojos azules. Buenos Aires: La Facultad.

Gálvez, M. (1938). Hombres en soledad. Buenos Aires: Club del Libro A.L.A.

Gálvez, M. (1939), Define Manuel Gálvez la Misión de Reconquista. Reconquista, 14 de noviembre, $1-2$.

Gálvez, M. (2001). El diario de Gabriel Quiroga. Opiniones sobre la vida argentina. Buenos Aires: Taurus.

Gálvez, M. (2002). Recuerdos de la vida literaria (I). Amigos y maestros de mi juventud en el mundo de los seres ficticios. Buenos Aires: Taurus.

Girard, A. (1996). El diario como género literario. Revista de Occidente, (182-181), 31-39.

Goldchluk, G. (1996). Manuel Gálvez en el campo intelectual argentino [en línea] (Trabajo final de grado). Universidad Nacional de La Plata. Facultad de Humanidades y Ciencias de la Educación. Recuperado de http://www.memoria.fahce.unlp.edu.ar/tesis/te.158/te.158.pdf (Fecha de consulta 15/12/2018).

Gramuglio, M. T. (2001). Estudio preliminar. En M. Gálvez, El diario de Gabriel Quiroga. Opiniones sobre la vida argentina (pp. 9-52). Buenos Aires: Taurus.

Grafton, A. (2007). La historia de las ideas. Preceptos y prácticas 1950-2000 y más allá, Primas - Revista de Historia Cultural, (2), 123-148.

Grinchpun, M. B. (2011). Un Poco de Violencia Será Indispensable. Guerra y fascismo en la obra de Manuel Gálvez. Anuario del Centro de Estudios Históricos "Prof. Carlos S. A. Segreti", (11), 191-224.

Gusmán, L. (2015). Los otros diarios. Página 12, 6/10/15, 1.

Halperin Donghi, T. (2005). El revisionismo histórico como visión decadentista de la historia nacional. Buenos Aires: Siglo XXI.

Irazusta R. y Irazusta J. (1982). La argentina y el imperialismo británico. Buenos Aires: Independencia.

Jitrik, N. (1969). Actualidad de Gálvez. Cahiers du monde hispanique et luso-brésilien, (13), 15-22. 
Kroeber, C. (1964). Rosas y la revisión de la historia argentina. Buenos Aires: Fondo Editor Argentino.

Mora, G. (1996). El cuento modernista hispanoamericano. Buenos Aires: Latinoamérica.

Mosse, G. (1998). La cultura europea del siglo XIX. Barcelona: Ariel.

LaCapra, D. (1997). Repensar la historia intelectual y leer textos. En E. J. Palti, “Giro lingüístico" e historia intelectual (pp. 237-295). Bernal: Universidad Nacional de Quilmes.

Palacio, E. (1948). ¿Se trata de elaborar, al fin, una Constitución para los argentinos? Hechos e Ideas, (54), 280-282.

Palacio, E. (1960). La historia falsificada. Buenos Aires: Peña Lillo.

Palti, J. E. (2014). ¿Las ideas fuera de lugar? Estudios y debates en torno a la historia políticointelectual latinoamericana. Buenos Aires: Prometeo.

Paya, C. y Cárdenas, E. (1978). El primer nacionalismo argentino en Manuel Gálvez y Ricardo Rojas. Buenos Aires: Peña Lillo.

Peña, D. (1906). Juan Facundo Quiroga. Buenos Aires: Coni hermanos.

Perez, J. A. (2006). Imaginación literaria y pensamiento propio. Buenos Aires: Corregidor.

Picard, H. R. (1981). El diario como género entre lo íntimo y lo público. Anuario de la Sociedad Española de Literatura General y Comparada, (4), 115-120.

Quattrocchi-Woisson, D. (1995). Los males de la memoria. Historia y política en la Argentina. Buenos Aires: EMECE.

Quijada, M. (1985). Manuel Gálvez: 60 años de pensamiento nacionalista. Buenos Aires: Centro Editor de América Latina.

Rodó, J. E. (1920). Ariel. Buenos Aires: Cervantes.

Rosa, J. M. (1968). Historia del revisionismo y otros ensayos. Buenos Aires: Merlín.

Rubio García, G. (2016). Los nacionalismos argentinos: un acercamiento al debate historiográfico en torno a sus figuras de la década de 1930. Historiografías, (13), 7494.

Rubio García, M. S. y Rubio García, G. (2016). De "vindicadores" a "revisionistas". (Re)interpretaciones de la historia en la primera mitad del siglo XX. David Peña y Raúl Scalabrini Ortiz. En L. M. Brezzo, M. G. Micheletti y M. B. Girardi (Comps.), VI Jornada de Discusión de Avances de Investigación en Historia Argentina: fuentes, problemas y métodos. Actas Digitales (pp. 281-312). Rosario: Facultad de Derecho y Ciencias Sociales del Rosario - UCA. Recuperado de http://www.institutohistoria.com.ar/uploadsarchivos/actas_digitales_vi_jornada_de _avances_2016.pdf (Fecha de consulta 10/9/2018).

Scalabrini Ortiz, R. (1940). Política británica en el Río de la Plata. Buenos Aires: Reconquista.

Scalabrini Ortiz, R. (1948). El capital, el hombre y la propiedad en la vieja y en la nueva Constitución. Buenos Aires: Reconquista.

Skinner, Q. (2007). Lenguaje, política e historia. Bernal: Universidad Nacional de Quilmes. 
Tato, M. I. (2009). Nacionalistas y conservadores, entre Yrigoyen y la década infame. En L. A. Bertoni y L. De Privitellio (Eds.), Conflictos en democracia: La vida política argentina entre dos siglos (pp. 149-170). Buenos Aires: Siglo XXI.

Terán, O. (2008). Historia de las ideas en la Argentina. Diez lecciones iniciales, 1910-1980. Buenos Aires: Siglo XXI.

Yurkievich, S. (1976). Celebración del modernismo. Barcelona: Tusquets.

Zanetti, S. (1994). Modernidad y religación: una perspectiva continental (1890-1916). En A. Pizarro (Ed.), América Latina: Palabra, Literatura e Cultura (pp. 489-534). São Paulo: UNICAMP.

Para citar este artículo:

Rubio García, Gonzalo (2020). El diario de Gabriel Quiroga: reflexiones de Manuel Gálvez ante el centenario de la Revolución de Mayo. Anuario de la Escuela de Historia Virtual, 17, 57-78. 